revised land management. But for 2008-2012 the official figure may be smaller, partly because of concerns over how sinks should be measured, says Frank Loy, Undersecretary of State for Global Affairs. Counting only some of the carbon trapped in sinks would also help to pacify countries with fewer forests and fields than the United States, he adds.

Loy argues that using the broad definition of sinks to meet the Kyoto targets is not cheating, as scientists agree that sinks play a role in reducing greenhouse-gas levels in the atmosphere. But how large this role is, and how it should be quantified, is another issue. This summer, the Intergovernmental Panel on Climate Change produced a report detailing the problems of measuring how much carbon is trapped and released in land-use strategies.

Loy thinks such difficulties can be overcome - sinks are "quite measurable", he says. But Eileen Claussen, president of the Pew Center on Global Climate Change, disagrees. She emphasizes the forest fire problem and points out that soil may become carbon-saturated sooner than expected. "Could these things be loopholes? Yes," she says.

Claussen believes that sinks should be counted to some extent, but questions the level to which the US proposal relies on them. "I don't think the US plan as conceived is what's going to be accepted internationally," she says.

William Moomaw, professor of international environmental policy at Tufts University in Massachusetts, calls the proposed system a huge accounting problem. $\mathrm{He}$ is concerned that it gives credits for reforestation, but misses instances of deforestation. "You can't just count the sinks and not count the sources," he says.

Moomaw also wonders whether countries will get credits for planting trees before 2008. Credit for planting should only count after it offsets emissions, as well as deforestation and development, he says. He also notes that different kinds of trees and soils have different capacities for holding carbon. Because of this complexity, Moomaw says the Kyoto Protocol should only count obvious, easily measurable debits and credits.

Moomaw is also concerned about the way the United States has emphasized buying other countries' emission credits, supporting emission reductions projects in developing countries, and relying on sinks, rather than adopting tough domestic measures to reduce carbon emissions. "We're looking for every possible way to show we are making a reduction without asking anyone [in the United States] to do anything," he says.

http://www.state.gov/www/global/global_issues/ climate/fs-000801_unfccc1_subm.html

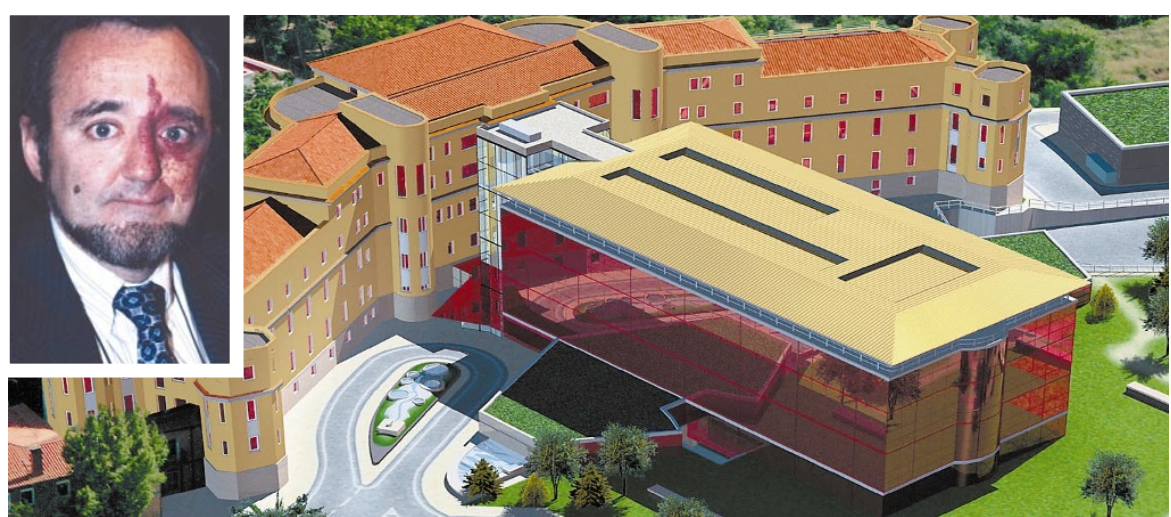

Shaky foundations? Barbacid (inset) warns against relying on industry money to build cancer centre.

\title{
Spanish biomedical centres face funding uncertainty
}

\section{Xavier Bosch, Barcelona}

When the Spanish government announced plans in September 1997 to open two worldclass research centres in cancer and cardiovascular disease, the move was widely welcomed. But there were immediately questions over their long-term support.

Now, it seems, the government is hoping that the two Madrid-based centres - the National Centre of Cancer Research (CNIO), due to open next spring, and the Institute of Cardiovascular Diseases (IICV), work on which will probably start in 2001 - will receive a hefty chunk of their funding from private industry.

The government had pledged to meet the financial needs of both, including their construction and equipment. But the new minister of health, Celia Villalobos, appointed in April after a general election, appears to be retreating from this commitment.

The ministry has now announced that it will raise Ptas5.5 billion (US $\$ 31$ million) this year from an agreement with Farmaindustria, a group of 240 drug companies. But this leaves the centres' long-term prospects in doubt.

Mariano Barbacid, head of CNIO and internationally known for his role in the discovery of human oncogenes, fears that the ministry may no longer fulfil its commitments - including providing Ptas 3.2 billion to CNIO's budget next year.

Barbacid says that he hopes this promise will not be dropped during the autumn's budget discussions. "The collaboration with Farmaindustria should come through research projects," he says. "Pharmaceutical companies should not finance infrastructure [of the $\mathrm{CNIO}]$, as this agreement is only for this year, and the future would be left uncertain.'

Farmaindustria spokesman Carlos Nicolás confirms that industry support is just for one year. "Nobody knows what will happen next year." Others claim that the agreement is part of a longer-term deal between the government

^ 2000 Macmillan Magazines Ltd and the pharmaceutical industry.

They point to a recent statement by finance minister Rodrigo Rato who announced the government's intention to "promote a pact with the pharmaceutical industry to avoid spending on drugs increasing at more than $8 \%$ a year".

Some believe that Villalobos wanted a quick fix to the research centres' money problems because she is more concerned about the broad funding of healthcare than research.

Although the IICV is not likely to open until 2002, it is due to receive Ptas1.7 billion this year to start construction work. Salvador Moncada, director of the Wolfson Institute for Biomedical Research at University College, London, who is said by some to have been asked to head the centre, is among those urging the Spanish government to make a long-term investment in research.

"A commitment to research does not just mean obtaining a one-off donation from the drug industry, but the stable and long-term financing needed to allow the development of a solid scientific base," says Moncada, an adviser on the creation of the centre.

By law, 1\% of Spain's health budget must be devoted to research. To reach this target, Moncada is proposing that the ministry guarantees providing at least $0.25 \%$, with the rest coming from the drug and food industries.

Given the Mediterranean diet's role in protecting against heart disease, "authorities should regard the food industry as a potentially important source of biomedical research support," says Moncada.

Villalobos appears to share Moncada's belief that industry should fund basic biomedical research. Shortly before the agreement with Farmaindustria was announced, she said that she was seeking "a stable, longterm solution to finance both the CNIO and the IICV that may eventually rely on a serious deal with the industry".

inttp://www.cnio.es 